\title{
LIFE-HISTORY TRADE-OFFS INFLUENCE DISEASE IN CHANGING CLIMATES: STRATEGIES OF AN AMPHIBIAN PATHOGEN
}

\author{
Douglas C. Woodhams, ${ }^{1,6}$ Ross A. Alford, ${ }^{2}$ Cheryl J. Briggs,,${ }^{3,7}$ Megan Johnson, ${ }^{4}$ \\ AND Louise A. Rollins-SMith ${ }^{5}$ \\ ${ }^{1}$ Department of Microbiology and Immunology, Vanderbilt University, A-5301 Medical Center North, \\ Nashville, Tennessee 37232 USA \\ ${ }^{2}$ School of Marine and Tropical Biology, James Cook University, Townsville, Queensland 4811 Australia \\ ${ }^{3}$ Department of Integrative Biology, University of California, Berkeley, California 94720-3140 USA \\ ${ }^{4}$ School of Public Health and Tropical Medicine, James Cook University, Townsville, Queensland 4811 Australia \\ ${ }^{5}$ Department of Microbiology and Immunology and Department of Pediatrics, Vanderbilt University, A-5301 Medical Center North, \\ Nashville, Tennessee 37232 USA
}

\begin{abstract}
Life-history trade-offs allow many animals to maintain reproductive fitness across a range of climatic conditions. When used by parasites and pathogens, these strategies may influence patterns of disease in changing climates. The chytrid fungus, Batrachochytrium dendrobatidis, is linked to global declines of amphibian populations. Short-term growth in culture is maximal at $17^{\circ}-25^{\circ} \mathrm{C}$. This has been used in an argument that global warming, which increases the time that amphibians spend at these temperatures in cloud-covered montane environments, has led to extinctions. Here we show that the amphibian chytrid responds to decreasing temperatures with trade-offs that increase fecundity as maturation rate slows and increase infectivity as growth decreases. At $17^{\circ}-25^{\circ} \mathrm{C}$, infectious zoospores encyst (settle and develop a cell wall) and develop into the zoospore-producing stage (zoosporangium) faster, while at $7^{\circ}-10^{\circ} \mathrm{C}$, greater numbers of zoospores are produced per zoosporangium; these remain infectious for a longer period of time. We modeled the population growth of $B$. dendrobatidis through time at various temperatures using delayed differential equations and observational data for four parameters: developmental rate of thalli, fecundity, rate of zoospore encystment, and rate of zoospore survival. From the models, it is clear that lifehistory trade-offs allow $B$. dendrobatidis to maintain a relatively high long-term growth rate at low temperatures, so that it maintains high fitness across a range of temperatures. When a seven-day cold shock is simulated, the outcome is intermediate between the two constant temperature regimes, and in culture, a sudden drop in temperature induces zoospore release. These trade-offs can be ecologically important for a variety of organisms with complex life histories, including pathogenic microorganisms. The effect of temperature on amphibian mortality will depend on the interaction between fungal growth and host immune function and will be modified by host ecology, behavior, and life history. These results demonstrate that $B$. dendrobatidis populations can grow at high rates across a broad range of environmental temperatures and help to explain why it is so successful in cold montane environments.
\end{abstract}

Key words: amphibian; Batrachochytrium dendrobatidis; Chytridiomycosis; climate; disease; life history; population decline; temperature; trade-off.

\section{INTRODUCTION}

Rapid declines in many amphibian populations are occurring globally (Stuart et al. 2004). Some of these declines are associated with the amphibian chytrid fungus, Batrachochytrium dendrobatidis, the agent of chytridiomycosis, an emerging infectious disease of amphibians (Berger et al. 1998, Daszak et al. 1999,

Manuscript received 3 November 2006; revised 8 October 2007; accepted 19 October 2007. Corresponding Editor: D. K. Skelly.

${ }^{6}$ Present address: Department of Biology, James Madison University, Harrisonburg, Virginia 22807 USA.

E-mail: dwoodhams@gmail.com

${ }^{7}$ Present address: Department of Ecology, Evolution and Marine Biology, University of California, Santa Barbara, California 93106-9610 USA.
2003). High infection prevalence and outbreaks of chytridiomycosis occur most frequently at upland sites and during the cold season (Berger et al. 1998, 2004, Bradley et al. 2002, Retallick et al. 2004, Woodhams and Alford 2005, Bosch and Martinez-Solano 2006, Lips et al. 2006, Rachowicz et al. 2006). Analysis of 56 sites in Australia indicated that the amphibian chytrid's presence was significantly related to temperature but not elevation or rainfall (Drew et al. 2006). Ecological niche modeling based on known localities of occurrence predicted an extensive range of suitable pathogen habitat, with a mean annual temperature of $13.1^{\circ} \mathrm{C}$ (Ron 2005). However, the density of the amphibian chytrid grown in culture increased most quickly (or had maximal short-term growth) at temperatures between $17^{\circ}$ and $25^{\circ} \mathrm{C}$ (Longcore et al. 1999, Piotrowski et al. 


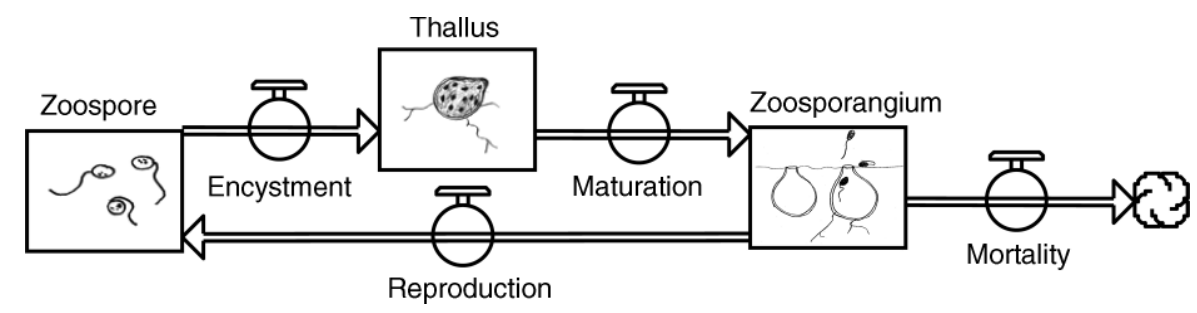

FIG. 1. The life cycle of Batrachochytrium dendrobatidis (a chytrid fungus), showing three life stages (zoospore, thallus, and zoosporangium) and rates of encystment, maturation, mortality, and reproduction. A resting spore stage may exist (Di Rosa et al. 2007, Morgan et al. 2007) but is not necessary for progression of chytridiomycosis.

2004). This growth pattern in culture has led to the suggestion that global warming is creating an optimal climate for chytridiomycosis in high-elevation regions of Central America, where increasing cloud cover may be modulating daily minimum and daily maximum temperatures to converge around a "chytrid thermal optimum" (Pounds et al. 2006). Piotrowski et al. (2004) demonstrated that after 23 days in culture at $10^{\circ} \mathrm{C}$, the density of $B$. dendrobatidis in culture converged with that in cultures grown at higher temperatures. Here we investigate whether this effect is due to nutrient limitation in culture or if there are life-history trade-offs that compensate for slower initial population growth at lower temperatures. We examine the hypothesis that the amphibian chytrid adapts to temperatures below $17^{\circ}$ $25^{\circ} \mathrm{C}$ through life-history trade-offs.

The amphibian chytrid develops through multiple stages in a single host. The life stages include a mobile infectious zoospore stage, a sessile developing thallus, and a zoospore-releasing zoosporangium (Fig. 1; also see Plate 1). Growth of the thallus may be colonial or a single unit termed monocentric (Longcore et al. 1999, Berger et al. 2005). In nutrient-rich medium, such as $1 \%$ tryptone, amphibian chytrid thalli mature extremely quickly through an exponential growth phase until the population levels off at a nutrient-limited stationary phase that releases few infectious zoospores. The stationary phase is reached in approximately 6-7 days at temperatures between $17^{\circ}$ and $28^{\circ} \mathrm{C}$ (Longcore et al. 1999, Piotrowski et al. 2004). This rapid limitation of growth is not likely to occur within living amphibian skin, and longer-term growth is investigated here.

The zoological literature suggests that trade-offs exist between fecundity and rate of maturation, particularly in animals with complex life histories. Mortality rate and maturation rate can vary with temperature, density, or other factors. Growth rate and fecundity can compensate for these changes to maximize reproductive fitness in marine invertebrates (Llodra 2002), insects (Howe 1967, Sisodia and Singh 2002), amphibians (Smith-Gill and Berven 1979, Werner 1986), fish (Kavanagh and Alford 2003, Savage et al. 2004), reptiles (Angilletta and Dunham 2003), and birds (Spencer and Bryant 2002). Trade-off strategies may be used by other organisms (Savage et al. 2004), including parasites and pathogens, and provide a framework for understanding disease emergence in the context of global change. Applying this framework to the amphibian chytrid fungus, which shows development through multiple life-history stages within a single host, suggests several a priori hypotheses. Specifically, this pathogen may adapt to changing temperatures by trading fecundity for maturation rate. We hypothesized that at relatively low temperatures, chytrid thalli would develop more slowly and mature at a larger size. Zoosporangia may thus produce more propagules at low temperatures than they do at higher temperatures. Infectivity, dependent upon the life span of the zoospore stage, may also be traded for rapid encystment and growth. That is, at lower temperatures, zoospores may survive longer. Batrachochytrium dendrobatidis grows well in culture and develops through all of the same life stages as on the keratinized skin of amphibians and the mouthparts of tadpoles (Berger et al. 1998, Longcore et al. 1999). Therefore, experiments in culture may be a good surrogate for modeling in vivo pathogen population changes while eliminating the effects of variation in host responses (Woodhams et al. 2006, 2007).

Here we present a series of laboratory experiments designed to quantify components of $B$. dendrobatidis life history. These experiments provide temperature-dependent parameter estimates that we incorporate into a population model that determines their net effects on long-term population growth rate.

\section{Methods}

\section{Quantifying zoospore survival and encystment}

We quantified $B$. dendrobatidis zoospore survival rate and encystment rate at different temperatures. For this experiment, $B$. dendrobatidis isolated from an eastern banjo frog, Limnodynastes dumerili, Victoria, Australia (isolate number 98-1469/10), was maintained at James Cook University, Townsville, Australia, in TGhL liquid medium (1.6\% tryptone, $4 \%$ gelatin hydrolysate, $0.5 \%$ lactose) in $25-\mathrm{cm}^{2}$ cell culture flasks. After $4 \mathrm{~d}$ incubation at $23^{\circ} \mathrm{C}$, the culture flasks were scraped to remove the attached cells and centrifuged at $980 \times g$ (or $9600 \mathrm{~m} / \mathrm{s}^{2}$ ) for $5 \mathrm{~min}$ to purify the zoospores in the supernatant. Zoospores were checked for activity and 
counted using a hemocytometer slide at $400 \times$ magnification. Zoospores were prepared at a concentration of $162 \times 10^{4}$ zoospores $/ \mathrm{mL}$, and $5 \mathrm{~mL}$ were placed in each of 12 sterile glass vials with TGhL liquid medium. Three vials were placed at each of four temperatures in incubators or in controlled-temperature rooms: (1) $28^{\circ} \mathrm{C}$, (2) $23^{\circ} \mathrm{C}$, (3) $14.5^{\circ} \mathrm{C}$, and (4) $4^{\circ} \mathrm{C}$. After placement at each temperature for $0,2,5,22$, and $45 \mathrm{~h}$, the numbers of zoospores were estimated by removing 10 $\mu \mathrm{L}$ of solution from gently mixed cultures and taking the mean zoospore count from two squares on a standard hemocytometer slide. Zoospores were classified as either active (swimming or moving) or inactive. Since zoospores move rapidly, counts of active zoospores were made at a single time point for each small square of the hemocytometer.

Over this short time period, the only processes affecting zoospore abundance are mortality and encystment (no production of new zoospores). Zoospores encysted on the sides of the glass flasks. We used motility as a surrogate measure for viability (Berger 2001) because nonmotile zoospores that did not encyst did not appear to develop into thalli in solution. Batrachochytrium dendrobatidis does not appear to produce a resting stage arising from zoospores (Longcore et al. 1999, Berger et al. 2005, Di Rosa et al. 2007). With these assumptions, the rate of change of live zoospores in the experiment is predicted to be: $d Z(t) / d t=$ $-\left(d_{Z}+m_{Z}\right) Z(t)$, where $Z(t)$ is the density of live zoospores, $d_{Z}$ is the per capita zoospore death rate, and $m_{Z}$ is the per capita encystment rate. Dead zoospores accumulate at: $d D(t) / d t=d_{Z} Z(t)$, where $D(t)$ is the density of dead zoospores. Therefore, the predicted densities of live and dead zoospores are

$$
Z(t)=Z(0) \exp \left[-\left(d_{Z}+m_{Z}\right) t\right]
$$

and

$$
D(t)=D(0)+d_{Z} Z(0)\left\{1-\exp \left[-\left(d_{Z}+m_{Z}\right) t\right]\right\} /\left(d_{Z}+m_{Z}\right)
$$

where $Z(0)$ and $D(0)$ are the initial densities of live and dead zoospores, respectively.

The parameter combination $\left(d_{Z}+m_{Z}\right)$ was estimated for each temperature as the slope of the trajectory of the log-transformed live zoospore density through time. The initial zoospore density (live + dead) was $162 \times 10^{4}$ zoospores/mL; however, the initial proportion of live zoospores in this sample was not measured directly. Therefore, $Z(0)$, which should be the same for all temperature treatments, was calculated as the average of the initial densities of live zoospores across the four temperature treatments, which were estimated for each treatment as the intercept of the regression $(\ln (Z(t))=$ $\left.\ln (Z(0))-\left(d_{Z}+m_{Z}\right) t\right)$. The parameter combination $\left(d_{Z}+\right.$ $m_{Z}$ ) was then calculated for each temperature with $Z(0)$ set to this common value. The initial density of dead zoospores, $D(0)$, was assumed to be the same for all temperature treatments and was calculated as $162 \times 10^{4}$ zoospores $/ \mathrm{mL}-Z(0)$. Parameter $d_{Z}$ was calculated for each temperature by least-squares fitting of Eq. 2 to the observed time series of dead zoospores, using the estimated value of $\left(d_{Z}+m_{Z}\right)$ for that temperature.

\section{Quantifying thallus maturation and zoospore production}

The life-history traits of thallus maturation (time to sporulation) and fecundity (number of zoospores produced) were experimentally quantified and examined for the effects of temperature and initial density. We grew the amphibian chytrid type isolate (JEL 197) under variable temperature regimes at Vanderbilt University. Eight culture flasks containing $10 \mathrm{~mL} 1 \%$ tryptone broth with $1 \%$ penicillin/streptomycin were each inoculated with $5 \times 10^{5}$ zoospores $/ \mathrm{mL}$. We obtained zoospores by the following method: We scraped culture flasks of $B$. dendrobatidis and applied $\sim 1.5 \mathrm{~mL}$ to $1 \%$ tryptone agar plates. Plates were dried for $\sim 1 \mathrm{~h}$ in a sterile hood, incubated for $7 \mathrm{~d}$ at $23^{\circ} \mathrm{C}$, and rinsed with $3 \mathrm{~mL}$ broth once and again after soaking for $20 \mathrm{~min}$. Thalli were removed by filtering broth through a $20-\mu \mathrm{m}$ Spectra/ Mesh nylon filter (Spectrum Laboratories, Rancho Dominguez, California, USA). Gently mixed zoospores in broth were counted on a hemocytometer slide as described in Quantifying zoospore survival and encystment and diluted in broth to the desired concentration. We placed four flasks into each of two treatments: $10^{\circ} \pm$ $0.5^{\circ} \mathrm{C}$ and $23^{\circ} \pm 0.5^{\circ} \mathrm{C}$. Two counts were made from each flask initially and each day for $14 \mathrm{~d}$. After gently mixing the culture flasks, $10 \mu \mathrm{L}$ was added to one side of the hemocytometer slide, and to the other side of the slide $10 \mu \mathrm{L}$ of zoospores diluted 1:10 in Lugol solution (Sigma Chemical, St. Louis, Missouri, USA) was added to kill and stain the zoospores. Numbers of active, inactive, and total stained zoospores were counted. The proportion of mean active to mean total (active plus inactive zoospores) was calculated at each time point. In addition, the mean live zoospores per initial live zoospores (at day 0) was calculated at each time point.

When $B$. dendrobatidis thalli reach maturity they become zoosporangia, release their zoospores, and then die (Longcore et al. 1999). In each flask, no zoospores remained active from the initial innoculum after the first day; however, these initial zoospores resulted in an observable pulse of zoospores a number of days later. We assumed that the zoospores in this first pulse were the first generation offspring of the initial zoospore inoculum. At each temperature we calculated the average time to sporulation $(\tau)$ and the total number of viable zoospores released per initial live zoospores present $(F)$ by least-squares fitting of the time series of the average number of live zoospores per initial live zoospore (from time $t=0$ through the end of the first pulse) to the output of the model:

$$
d Z / d t=R(t)-\left(m_{Z}+d_{Z}\right) Z(t)
$$

where the parameter combination $\left(m_{Z}+d_{Z}\right)$ at each 
temperature was taken to be the value calculated in the experiments described in Quantifying zoospore survival and encystment, above (for $10^{\circ} \mathrm{C}$, the value was interpolated from the experimental results at $4^{\circ}$ and $\left.14.5^{\circ} \mathrm{C}\right) . R(t)$ is the recruitment of new active zoospores representing the progeny of the initial inoculum of zoospores at time $t$ $=0$. A delayed gamma distribution was used for $R(t)$, to allow for the observed variability in the time to sporulation. The delayed gamma distribution has density function $R(t)=F(t-\phi)^{(a-1)} \exp \{-(t-\phi) / s\} /\left(s^{a} \Gamma(a)\right)$, where $a$ is the shape parameter, $s$ is the scale parameter, $\phi$ is the lag, and $\Gamma(a)$ is a gamma function. $F$ is the total number of viable zoospores produced per initial zoospore, and $\tau=\phi+a \times s$ is the mean time to sporulation. The fitting was performed using the optim function in the program R (R Development Core Team 2007) to determine the values of $F, \phi, a$, and $s$ that minimized the sum-of-squares difference between the output of Eq. 3 and the observed values.

To examine the effect of changing temperature on the quantity and timing of zoospore production, 12 flasks were inoculated with zoospores (JEL 197) in $1 \%$ tryptone broth with $1 \%$ penicillin/streptomycin antibiotic, and zoospores were counted daily as described in Quantifying zoospore survival and encystment. All flasks were incubated for $5 \mathrm{~d}$ in a constant $26.5^{\circ} \mathrm{C}$ incubator at Vanderbilt University. Flasks were then placed at: (1) $7.5^{\circ} \mathrm{C}$, (2) $23.5^{\circ} \mathrm{C}$, or (3) $26.5^{\circ} \mathrm{C}$ and monitored for $10 \mathrm{~d}$.

Thallus maturation was also measured by examining cultures (JEL 197) grown in 35-mm glass bottom culture dishes (Mat Tek, Ashland, Massachusetts, USA) under $400 \times$ magnification with an inverted microscope (Olympus CK40; Olympus, Melville, New York, USA). Living colonies attached to the glass slide were monitored daily for motile zoospores. Time to sporulation was recorded at the first time point motile zoospores were observed. Culture dishes were inoculated with 10, 100, 500, or 1000 zoospores $/ \mu \mathrm{L}$ in $1 \%$ tryptone broth and grown at either $10^{\circ}$ or $23^{\circ} \mathrm{C}$. We analyzed digital photographs with ImageTool version 2.0 (University of Texas Health Science Center, San Antonio, Texas, USA) and quantified the effect of initial density on development (time to sporulation and size of thalli). Time to zoospore release could not be used to estimate model parameter $\tau$ in this experiment because zoospores were released over a period of days and were not quantified.

To measure the effects of density on $B$. dendrobatidis growth, zoospores were diluted with TGhL liquid medium to concentrations between $1 \times 10^{4}$ and $1 \times$ $10^{7}$, and $100 \mu \mathrm{L}$ were pipetted into five replicate wells on 96-well plates. Plates were held in an incubator at $23^{\circ} \mathrm{C}$ for $7 \mathrm{~d}$. Growth within the wells was measured daily by optical density at $490 \mathrm{~nm}$ on an MRX Microplate Reader (DYNEX Technologies, Chantilly, Virginia, USA). We quantified the effect of initial zoospore density on culture growth. Density effects were not included in the model describing temperature-related trade-offs.

\section{Building a model of long-term population growth rate}

We developed a stage-structured model of $B$. dendrobatidis population growth, using the experimentally determined parameter values. The model incorporates the temperature-dependent life-history strategies observed in the experiments and determines their net effects on long-term population growth rate. The model divides the population of $B$. dendrobatidis into a mobile infectious zoospore stage, $Z$, and a sessile developing sporangium stage, $S$. The zoospore-releasing zoosporangium stage is short-lived relative to the other stages; it is assumed that zoosporangia release zoospores after a fixed (but temperature-dependent) development time. For simplicity, this model assumes a fixed lag between the time that zoospores encyst and the time at which the resulting sporangia start to produce new zoospores, although some variability in this time lag was observed in the experimental results in Quantifying thallus maturation and zoospore production, above. The developing sporangia stage, $S$, incorporates both the thallus and zoosporangium stages until zoospores are released. Therefore the zoospore-releasing stage does not need to be modeled explicitly.

The growth of the population is modeled as a linear system of delayed-differential equations:

$$
\begin{aligned}
& \frac{d Z(t)}{d t}=f M_{S}(t)-m_{Z} Z(t)-d_{Z} Z(t) \\
& \frac{d S(t)}{d t}=m_{Z} Z(t)-M_{S}(t)-d_{S} S(t) \\
& M_{S}(t)=m_{Z} Z(t-\tau) \exp \left\{-d_{S} \tau\right\}
\end{aligned}
$$

where $M_{S}(t)$ is the maturation rate out of the developing thallus stage.

The first term in Eq. 4 represents the instantaneous rate of production of mobile zoospores. Each developing thallus produces $f$ zoospores at the instant that it matures into the zoospore-releasing stage (which occurs at rate $\left.M_{S}(t)\right)$. The second term in Eq. 4, which is equal to the first term of Eq. 5, represents the rate at which zoospores settle out of the mobile zoospore stage and become developing thalli. The variable $m_{Z}$ is the per capita rate of encystment of zoospores per hour. This constant rate of encystment means that the model assumes that the time spent in the mobile zoospore stage is exponentially distributed, with an average duration of $1 / m_{Z}$ (in the absence of loss due to other causes). Variables $d_{Z}$ and $d_{S}$ are density-independent per capita death rates of zoospores and developing thalli, respectively. $\tau$ is the time from zoospore encystment until production of zoospores from the zoosporangium. Therefore, the maturation rate out of the developing thallus stage, $M_{S}(t)$ in Eq. 6 is equal to the rate that developing zoospores entered that stage $\tau$ hours ago, multiplied by the probability of surviving through those $\tau$ hours. We modeled the populations of active 


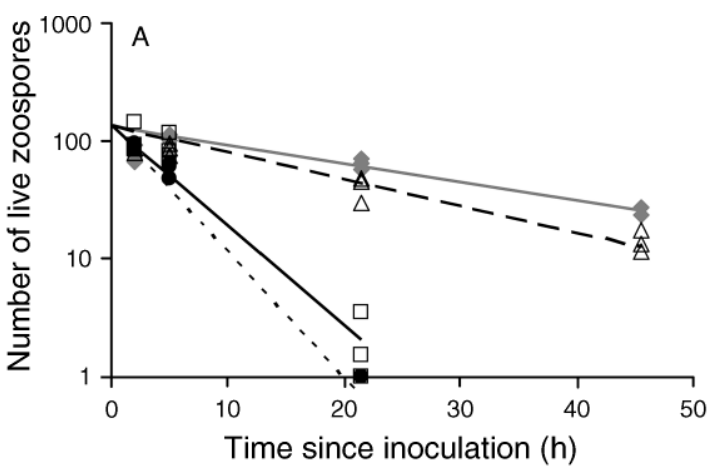

$$
\begin{aligned}
& \longrightarrow \quad 4^{\circ} \mathrm{C} ; m_{z}+d_{z}=0.036, R^{2}=0.70 \\
& -\triangle \quad 14.5^{\circ} \mathrm{C} ; m_{z}+d_{z}=0.052, R^{2}=0.87 \\
& \square-23^{\circ} \mathrm{C} ; m_{z}+d_{z}=0.194, R^{2}=0.93 \\
& --28^{\circ} \mathrm{C} ; m_{z}+d_{z}=0.25, R^{2}=0.87
\end{aligned}
$$
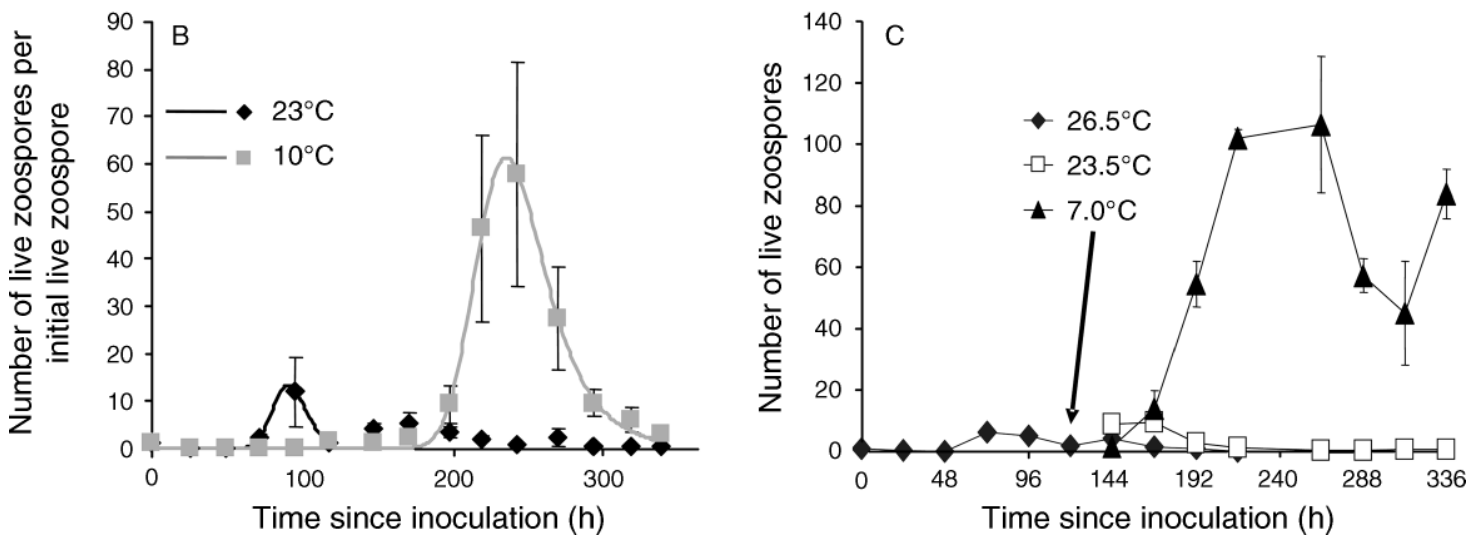

FIG. 2. Empirical parameterization of the model. (A) Zoospore mortality (model parameter $d_{Z}$ ) and the loss of zoospores from solution through time due to encystment (model parameter $m_{Z}$ ) measured at four temperatures. The slope of the regression line is the quantity $\left(m_{Z}+d_{Z}\right)$ at each temperature. Note the log scale for population size. (B) Live zoospores per initial live zoospore (mean $\pm \mathrm{SE}$ ) measured through time at $10^{\circ}$ and $23^{\circ} \mathrm{C}$. The mean time to sporulation $(\tau)$ and the total number of viable zoospores released per initial live zoospore present $(F)$ were calculated for each temperature by least-squares fitting of the time series data (from time $t=0$ through the end of the first pulse) to the model output of Eq. 3. (C) Zoospore production (mean \pm SE) after an incubation period of $5 \mathrm{~d}$ at constant $26.5^{\circ} \mathrm{C}$. The arrow indicates the time at which cultures were moved to different temperatures.

zoospores and living thalli through time at constant $10^{\circ} \mathrm{C}$ and constant $23^{\circ} \mathrm{C}$. Simulations of the model at constant temperatures were performed using a fourth/ fifth-order Runge-Kutta algorithm, using the Solver software (Gurney et al. 1998), which handles time lags efficiently. Initial conditions for the simulations were 100 zoospores and no sporangia in any age class (i.e., $Z(0)=100$, and $S(t)=0$ for all $t \leq 0)$.

The long-term intrinsic rate of increase of the $B$. dendrobatidis population (actually the eigenvalue, $\lambda$ ) can be calculated from the characteristic equation:

$$
F m_{Z} \exp \{-\lambda \tau\}-\lambda-\mu=0
$$

where $F=f \exp \left\{-d_{S} \tau\right\}$ is the effective number of zoospores produced per individual entering the thallus stage and $\mu=m_{Z}+d_{Z}$. Unfortunately it is not possible to produce an analytical expression for $\lambda$, but it can be solved for numerically.

Natural thermal conditions experienced by $B$. dendrobatidis in a complex environment include temperature fluctuations and host behavioral adjustments. We considered populations developing through changing temperatures, or "cold shock." When temperatures changed, we used the weighted average of the model parameters considering the time spent at each temperature, rather than locking the zoospores or thalli into development at the rates of the initial temperature. In order to simulate the population in a fluctuating temperature environment, we discretized the model on an hourly time step and calculated parameters based on the temperatures experienced by each hourly cohort (see Appendix). We simulated a population at $23^{\circ} \mathrm{C}$ experiencing a one-week long cold shock to $10^{\circ} \mathrm{C}$ (similar to the experiment shown in Fig. 2B) to determine its effect on long-term population growth rate.

In this model we have not included the observed effects of inoculum density on the rate of thallus maturation (Fig. 3), because any resource limitation resulting in density-dependent demographic rates on amphibian skin under natural conditions are likely to be different from those observed in culture.

\section{RESULTS}

\section{Quantifying zoospore survival and encystment}

We predicted that at low temperatures zoospores may trade rapid encystment for increased survival. Zoospores 

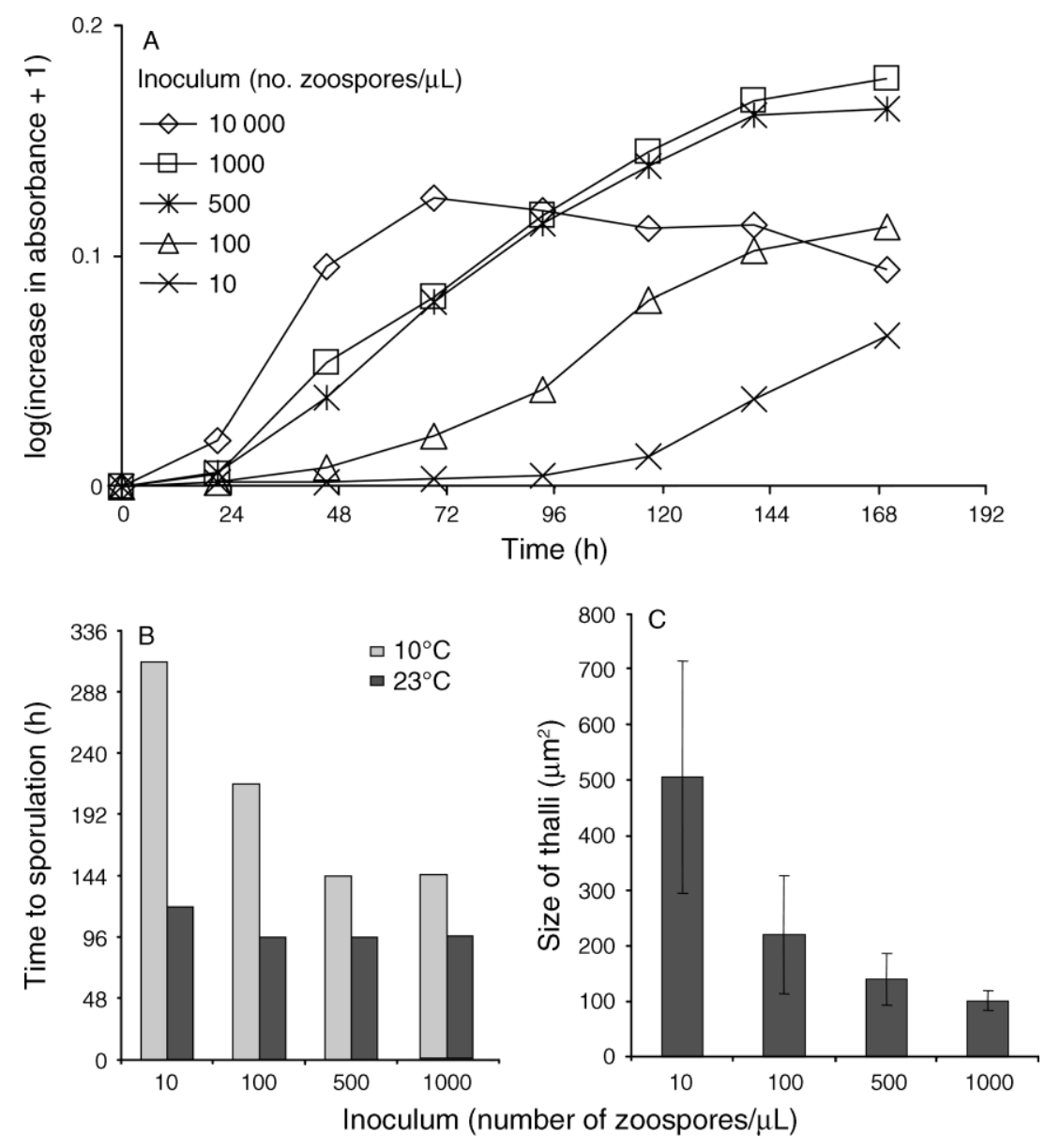

FIG. 3. Effects of initial density of zoospores on: (A) the pattern of Batrachochytrium dendrobatidis growth in culture, measured as the log of the increase in optical density measured at $490 \mathrm{~nm} \times 10^{3}+1$ (means; standard errors are too small to be visible); (B) the time to maturation, measured in hours to sporulation, the first time point at which zoospores were released; and (C) the size of thalli (area, mean $\pm \mathrm{SE}$ ) calculated from digital images. Inoculum refers to the number of zoospores added per microliter of the culture medium.

were slowly lost from solution at $10^{\circ} \mathrm{C}$ due to encystment (4\% of zoospores per hour). At $23^{\circ} \mathrm{C}$, zoospores were lost from solution more quickly due to encystment (17.8\% of zoospores per hour). Zoospore mortality, including loss of infectivity, was $0.3 \%$ per hour at $10^{\circ} \mathrm{C}$ and $1.61 \%$ per hour at $23^{\circ} \mathrm{C}$. Thus, as predicted, zoospores died and encysted more quickly as temperature increased (Fig. 2A, Table 1).

\section{Quantifying thallus maturation and zoospore production}

At low temperatures thalli took longer to mature into zoosporangia, but more zoospores were produced per zoosporangium than at higher temperatures (Fig. 2B). The maturation time of thalli was $\sim 87.7 \mathrm{~h}$ at $23^{\circ} \mathrm{C}$, but $222.7 \mathrm{~h}$ at $10^{\circ} \mathrm{C}$, given an inoculum of 500 zoospores $/ \mu \mathrm{L}$. When mature, the number of zoospores produced (free zoospores counted in culture) per initial zoospore inoculated was $\sim 64.8$ zoospores per initial zoospore at $23^{\circ} \mathrm{C}$ and 160.5 zoospores per initial zoospore at $9^{\circ} \mathrm{C}$.
The amphibian chytrid is temperature sensitive and can be killed by temperatures exceeding $30^{\circ} \mathrm{C}$ in vitro and in vivo (Longcore et al. 1999, Woodhams et al. 2003, Berger et al. 2004, Piotrowski et al. 2004). Close to the maximal temperature tolerance for $B$. dendrobatidis few zoospores were released (Figs. 2 and 4). However, when temperatures were suddenly reduced from $26.5^{\circ}$ to $7.0^{\circ} \mathrm{C}$, zoospore production greatly increased within $3 \mathrm{~d}$ (Fig. 2C). This increase in zoospore production was not observed when temperatures were suddenly reduced from $26.5^{\circ}$ to $23.5^{\circ} \mathrm{C}$ (Fig. 2C).

Batrachochytrium dendrobatidis cultures grew more quickly when inoculated with larger numbers of zoospores (Fig. 3A). Zoospores alone could not be quantified by optical density. At $23^{\circ} \mathrm{C}$, motile zoospores were observed after 4-5 d regardless of initial density. At $10^{\circ} \mathrm{C}$, the initial zoospore density had a large effect on time to zoospore production; the time to thallus maturation was longer in cultures with lower initial density (Fig. 3B). 
TABLE 1. Rates of zoospore mortality and encystment per hour under four temperature conditions for Batrachochytrium dendrobatidis (a chytrid fungus) isolated from an eastern banjo frog Limnodynastes dumerilli (98-1469/10).

\begin{tabular}{ccc}
\hline \hline $\begin{array}{c}\text { Temperature } \\
\left({ }^{\circ} \mathrm{C}\right)\end{array}$ & $\begin{array}{c}\text { Zoospore death } \\
\text { rate, } d_{Z}\left(\mathrm{~h}^{-1}\right)\end{array}$ & $\begin{array}{c}\text { Zoospore encystment } \\
\text { rate, } m_{Z}\left(\mathrm{~h}^{-1}\right)\end{array}$ \\
\hline 4.0 & $2.7 \times 10^{-3}$ & $3.4 \times 10^{-2}$ \\
14.5 & $3.5 \times 10^{-3}$ & $5.2 \times 10^{-2}$ \\
23.0 & $1.6 \times 10^{-2}$ & 0.18 \\
28.0 & $4.1 \times 10^{-2}$ & 0.21 \\
\hline
\end{tabular}

When grown for $5 \mathrm{~d}$ at constant $23^{\circ} \mathrm{C}$, the size of thalli was smaller at higher densities (Pearson correlation, $r_{35}$ $=-0.344, P=0.04$; Fig. 3C). At higher densities, thalli grew and matured more quickly than at lower densities; they also grew to a smaller size. The number of zoospores produced per zoosporangium grown under different density conditions was not measured.

Growth form in culture was also affected by temperature (Fig. 4). Very large colonial growth structures $(30-40 \mu \mathrm{m}$ diameter) were observed in cultures grown at $23^{\circ} \mathrm{C}$ (Fig. 4B) but not at $10^{\circ}$ or $26^{\circ} \mathrm{C}$ (Fig. 4A, C). Although normally spherical (Longcore et al. 1999), thalli became angular at $10^{\circ} \mathrm{C}$. Thalli at $10^{\circ}$ and $26^{\circ} \mathrm{C}$ were more often monocentric, less clumped, and more evenly distributed than at $23^{\circ} \mathrm{C}$.

\section{Modeled long-term population growth rate}

For the best estimates of the parameters from our data (Table 2), the population model predicts that $B$. dendrobatidis will have a higher intrinsic rate of increase at $23^{\circ} \mathrm{C}\left(\lambda=0.044 \mathrm{~h}^{-1}\right)$ than at $10^{\circ} \mathrm{C}\left(\lambda=0.021 \mathrm{~h}^{-1}\right)$. Fig. 5 illustrates the effects on the long-term population growth rate of the trade-off observed in this species between fecundity ( $F$, the number of zoospores produced per zoosporangium) and time to sporulation $(\tau)$. The two surfaces in this figure show this relationship when the other two parameters in the model, the zoospore mortality $\left(m_{Z}\right)$ and encystment $\left(d_{Z}\right)$ rates, are set to the default values for either $10^{\circ}$ or $23^{\circ} \mathrm{C}$. In terms of their net effects on long-term population growth rate, the increased fecundity at $10^{\circ} \mathrm{C}$ is not sufficient to offset the increased time to sporulation at this temperature, such that overall population growth rate is higher at the higher temperature (Fig. 5).

Fig. 6 shows simulations of the growth of populations of $B$. dendrobatidis over $50 \mathrm{~d}$ starting from 100 zoospores, using the default parameter values at $10^{\circ}$ and $23^{\circ} \mathrm{C}$ (Table 2). In the long term, the population density at the lower temperature remains below that at the higher temperature, but maintains a relatively high growth rate. Starting from 100 zoospores, after $50 \mathrm{~d}$ at $10^{\circ} \mathrm{C}$, the model predicts almost $10^{12}$ live sporangia and $\sim 10^{24}$ live sporangia at $23^{\circ} \mathrm{C}$ (Fig. 6). Assuming an infection threshold of $\sim 10^{7}-10^{8}$ sporangia beyond which amphibian mortality occurs (Carey et al. 2006), this model predicts mortality at $\sim 360 \mathrm{~h}$ at $23^{\circ} \mathrm{C}$ and $\sim 700 \mathrm{~h}$ at $10^{\circ} \mathrm{C}$ (Fig. 6), in the absence of host defenses. For susceptible amphibian species, mortality of infected hosts from chytridiomycosis can occur as fast as 18 and $48 \mathrm{~d}$ post-infection and varies with species and environmental conditions (Woodhams et al. 2003, 2007, Berger et al. 2004, Blaustein et al. 2005). Infection by even one zoospore can lead to mortality in some species (Carey et al. 2006).

Fig. 6 also demonstrates the effects of a cold shock on the growth of a $B$. dendrobatidis population over $50 \mathrm{~d}$. This simulation was started at $23^{\circ} \mathrm{C}$, and after $400 \mathrm{~h}$ the temperature was reduced to $10^{\circ} \mathrm{C}$ for a period of $7 \mathrm{~d}$ and then brought back up to $23^{\circ} \mathrm{C}$. The cold shock led to a

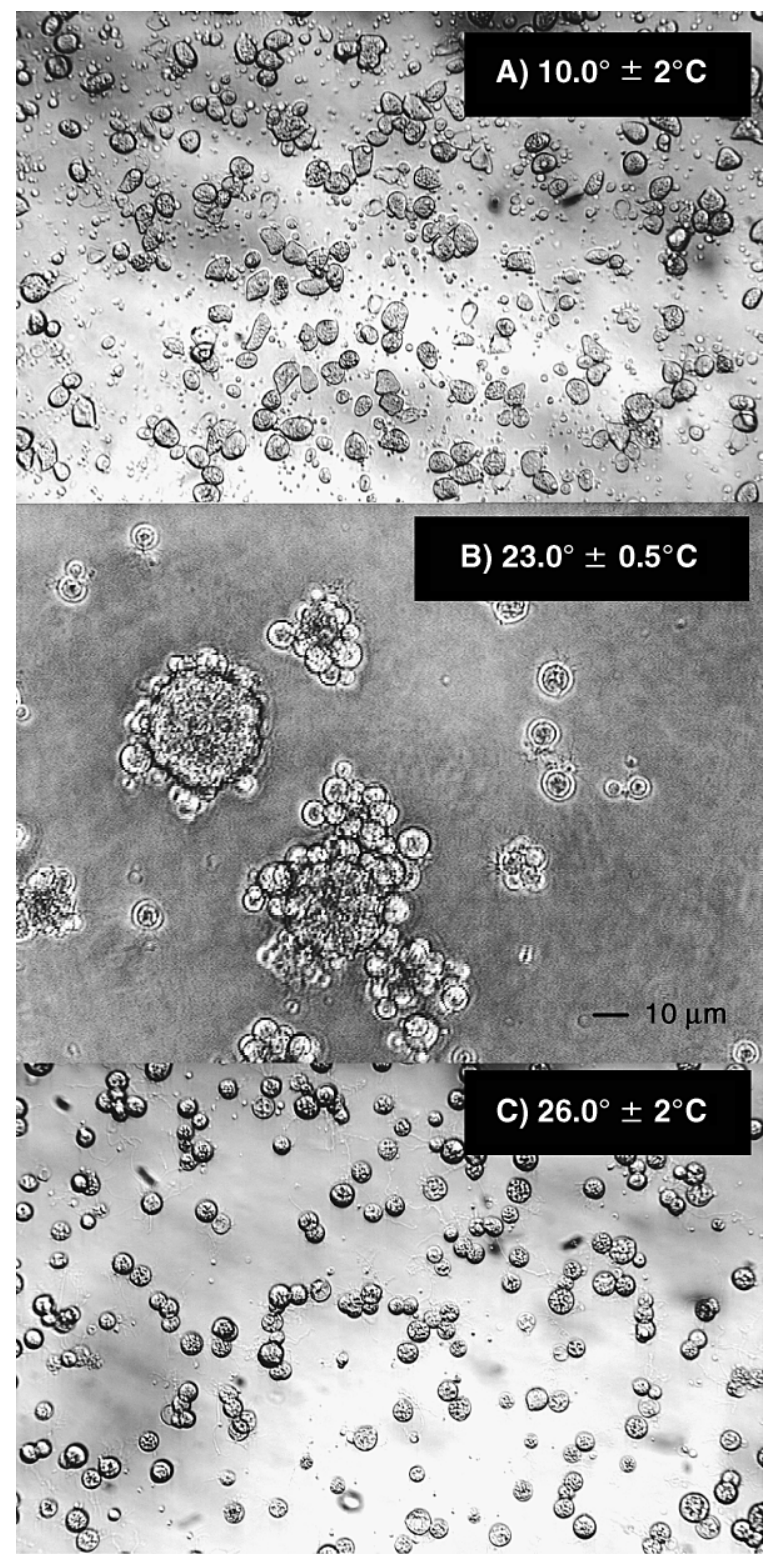

FIG. 4. Photographs of Batrachochytrium dendrobatidis grown for $8 \mathrm{~d}$ in culture at $10^{\circ}, 23^{\circ}$, and $26^{\circ} \mathrm{C}(400 \times$ magnification). Note (A) the irregular shape of zoosporangia and abundance of zoospores at $10^{\circ} \mathrm{C},(\mathrm{B})$ colonial growth at $23^{\circ} \mathrm{C}$, and $(\mathrm{C})$ spherical thalli with lack of zoospores at $26^{\circ} \mathrm{C}$. 


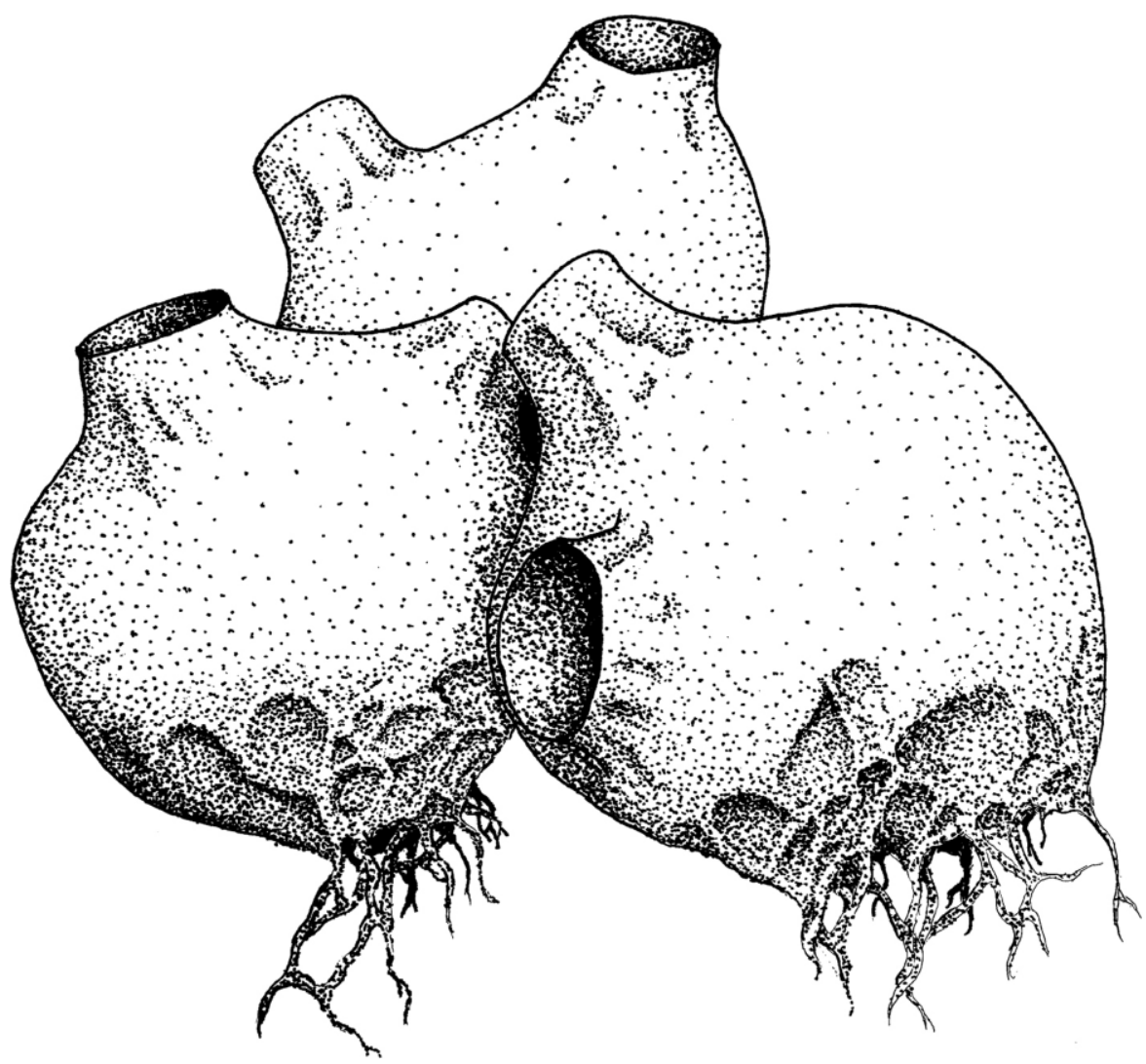

Plate 1. Artistic representation of the zoosporangium stage of the fungus Batrachochytrium dendrobatidis. Artwork by Robert M. Brucker, James Madison University.

short-term decrease in the population growth rate, and the density of sporangia resulting after $50 \mathrm{~d}$ was intermediate between the constant temperature regimes.

\section{DisCUSSION}

Chytridiomycosis epizootics and high infection prevalence often occur during cold seasons or at high elevations (Berger et al. 1998, 2004, Bradley et al. 2002, Retallick et al. 2004, Woodhams and Alford 2005, Bosch and Martinez-Solano 2006, Lips et al. 2006, Rachowicz et al. 2006). Temperature-induced trade-offs in pathogen life-history characteristics may contribute to these biogeographic patterns of disease. We modeled population trajectories at constant $10^{\circ}, 23^{\circ}$, or $23^{\circ} \mathrm{C}$ with a short $10^{\circ} \mathrm{C}$ cold shock and found that the fungus is

TABLE 2. Best parameter estimates for a model of amphibian chytrid zoospore production and size of colony through time at $10^{\circ}$ and $23^{\circ} \mathrm{C}$.

\begin{tabular}{|c|c|c|c|}
\hline Parameter & Description & $10^{\circ} \mathrm{C}$ & $23^{\circ} \mathrm{C}$ \\
\hline$F$ & $\begin{array}{l}\text { no. viable zoospores produced } \\
\text { per zoosporangium }\end{array}$ & 160.5 & 64.8 \\
\hline$\tau$ & mean no. hours to sporulation & 222.7 & 87.7 \\
\hline$d_{Z}$ & $\begin{array}{l}\text { per capita zoospore mortality } \\
\text { per hour }\end{array}$ & 0.003 & 0.0161 \\
\hline$m_{Z}$ & $\begin{array}{l}\text { per capita zoospore encystment } \\
\text { per hour }\end{array}$ & 0.04 & 0.178 \\
\hline
\end{tabular}

predicted to have the highest long-term growth rate at the higher temperature. However, the long-term growth rate remains high over a wide range of temperatures. Our results support the chytrid thermal-optimum hypothesis, since they indicate that increases in environmental temperature will increase the rate of growth of $B$. dendrobatidis populations on hosts, until temperatures are above the optimal thermal range for the pathogen. Our results also indicate that the effects of variable environmental temperatures are likely to be complex; while a short period of "cold shock" delayed population growth in our simple model (Fig. 6), our laboratory experiments indicated that short periods of "cold shock" may stimulate the release of zoospores, which could compensate or even overcompensate for temporary decreases in the rate of pathogen population growth. Because each zoosporangium releases many more zoospores at lower temperatures, infected frogs may be more likely to transmit the infection. This effect could be compounded by their longer survival.

Adaptation to a range of thermal conditions is facilitated by trade-offs between survival and encystment and between fecundity and maturation rate. These trade-offs operate in a variety of other organisms and act to maximize reproductive fitness over a range of environmental conditions (Wilbur and Collins 1973, 


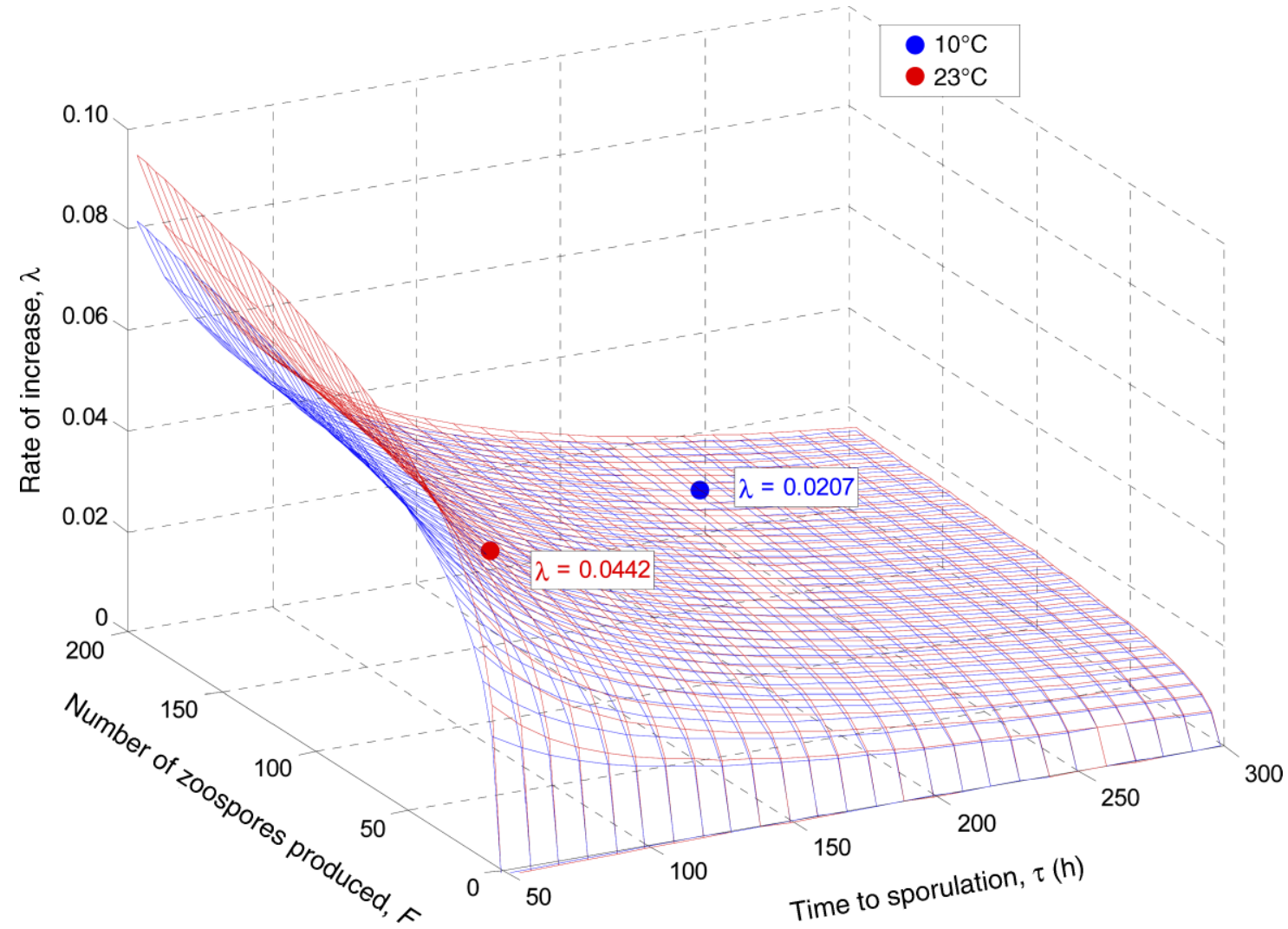

FIG. 5. Intrinsic rate of increase $(\lambda)$ for Batrachochytrium dendrobatidis population predicted by the constant-temperature model. Surfaces show the effects of varying the fecundity $(F$, the number of zoospores produced per zoosporangium) and the time to sporulation $(\tau)$, with the other two parameter values held at their best estimates (Table 2 ) for $23^{\circ} \mathrm{C}$ ( $\operatorname{shown}$ in red, $m_{Z}=0.178, d_{Z}$ $=0.0161$ ) and $10^{\circ} \mathrm{C}$ (shown in blue, $m_{Z}=0.04, d_{Z}=0.003$ ). The two circles on the graph show the intrinsic rate of increase $(\lambda)$ for the best estimates of $F$ and $\tau$ at $23^{\circ} \mathrm{C}$ (red, $F=64.8$ zoospores, $\tau=87.7 \mathrm{~h}$ ) and $10^{\circ} \mathrm{C}$ (blue, $F=160.5$ zoospores, $\tau=222.7 \mathrm{~h}$ ).

Smith-Gill and Berven 1979, Werner 1986, Kavanagh and Alford 2003, Savage et al. 2004). Thus, we show that an ecological framework often observed in zoological systems applies to a microbial pathogen.

Life-history trade-offs allow the amphibian pathogen $B$. dendrobatidis to maintain its fitness across a broad range of temperatures. If development of fatal chytridiomycosis is directly linked to pathogen population size (Carey et al. 2006), then pathogenicity may also be maintained by these trade-offs, at least in controlled experiments in which host factors such as behavior are constrained. Few experiments have tested the effects of temperature on living hosts infected with $B$. dendrobatidis, but these examples support our model. Carey et al. (2006) exposed boreal toads, Bufo boreas, to $B$. dendrobatidis at $12^{\circ}$ and $23^{\circ} \mathrm{C}$. Survival time was not statistically significantly different between these temperature treatments. Berger et al. (2004) exposed great barred frogs, Mixophyes fasciolatus, to B. dendrobatidis at $17^{\circ}$ and $23^{\circ} \mathrm{C}$ and found no significant difference in survival time. Infected orange-eyed treefrogs, Litoria chloris, survived longer under naturally fluctuating temperatures between $13.5^{\circ}$ and $23.2^{\circ} \mathrm{C}$ with or without a 2-d exposure to $8^{\circ} \mathrm{C}$ than frogs kept at constant $20^{\circ} \mathrm{C}$
(Woodhams et al. 2003). Although naturally warm conditions may inhibit disease (Woodhams et al. 2003, Berger et al. 2004), the fungus appears to maintain pathogenicity over a broad range of lower temperatures. We found that life-history trade-offs facilitate the fitness of $B$. dendrobatidis in colder environments.

\section{Zoospore survival and encystment}

Batrachochytrium dendrobatidis zoospores are clearly active for a longer time in cold conditions than in relatively warmer conditions (Fig. 2A, Table 1). This confirms a finding by Berger (2001), who collected $B$. dendrobatidis zoospores into distilled water and used motility as a measure of survival time at two temperatures, $4^{\circ}$ and $23^{\circ} \mathrm{C}$. She found that few zoospores were active after $24 \mathrm{~h}$ and that more zoospores survived at $4^{\circ} \mathrm{C}$ than at $23^{\circ} \mathrm{C}$. Hyatt et al. (2007) quantified zoospores by flow cytometry and also found that zoospores came out of solution faster at $23^{\circ} \mathrm{C}(\sim 2.26 \%$ per hour) than at $4^{\circ} \mathrm{C}(\sim 0.43 \%$ per hour $)$. Zoospores may therefore move greater distances before encysting in cold conditions, and they may be infective for a longer period of time than in warmer conditions. Formation of monocentric thalli (single individuals) rather than 


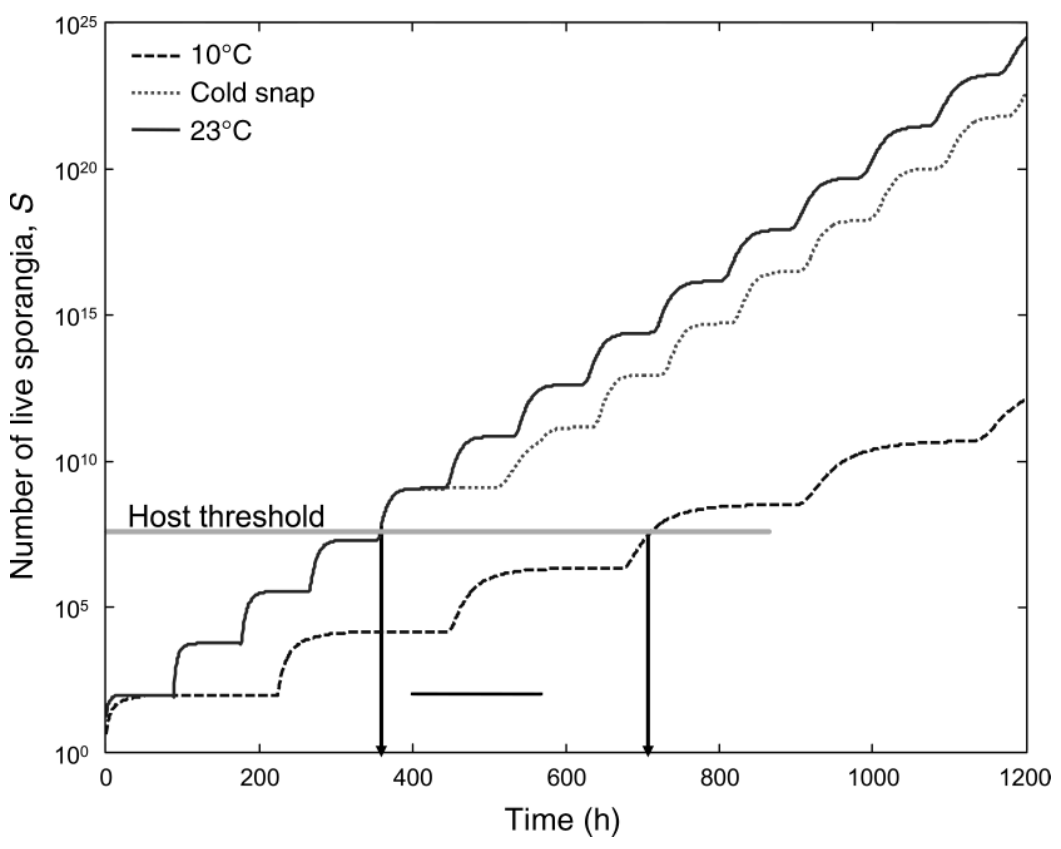

FIG. 6. Model simulations of Batrachochytrium dendrobatidis population increase over $50 \mathrm{~d}(1200 \mathrm{~h})$ at $10^{\circ}$ and $23^{\circ} \mathrm{C}$ with the best parameter estimates (Table 2). Also shown is a simulated cold shock in which the temperature is $23^{\circ} \mathrm{C}$ until $400 \mathrm{~h}$ into the simulation. At $t=400 \mathrm{~h}$, the temperature is reduced to $10^{\circ} \mathrm{C}$ for a period of one week and then brought back up to $23^{\circ} \mathrm{C}$ (dotted line). The parameter values at variable temperatures reflect the weighted averages of the parameter values at $10^{\circ}$ and $23^{\circ} \mathrm{C}$, depending upon the number of hours spent at each of the two temperatures (see Appendix). The host threshold line indicates the theoretical maximum population of living $B$. dendrobatidis sporangia able to infect host amphibian skin before causing mortality $\left(10^{7}-10^{8}\right.$ sporangia; Carey et al. 2006). Arrows indicate the predicted time to host mortality at each temperature.

colonies may be favored at low temperatures (Fig. 4). Zoospores encysting quickly may add to the size of colonies, whereas zoospores surviving longer and moving greater distances may start more colonies, perhaps adding to the surface area of skin covered by the fungus.

\section{Thallus maturation and zoospore production}

These results have important implications for understanding disease virulence and transmission. Transmission efficiency is likely increased at lower temperatures where it appears that larger numbers of zoospores are produced per zoosporangium, and these are likely to remain infectious for a longer period of time than at warmer temperatures. The number of active zoospores counted per inoculated active zoospore after one generation approximates the number of zoospores produced per zoosporangium but may be an underestimate due to factors such as mortality of inoculated zoospores and the effect of density on the continued development of encysted zoospores (Longcore et al. 1999) (Fig. 3). Careful microscopy is needed to confirm the number of zoospores inside fully developed zoosporangia under various conditions in vitro and in vivo. Estimates in the literature range from 4 to 150 zoospores per zoosporangium (Berger et al. 1999, Annis et al. 2004). Here we estimate 65-161 zoospores per zoosporangium (Table 2).
We found that at increasing density, $B$. dendrobatidis grew faster (Fig. 3A) and matured faster (Fig. 3B). However, zoosporangia grew to a smaller size, and this may indicate that fewer zoospores are produced per zoosporangium at higher densities (Fig. 3C). The net effect of these changes could cause the rate of population growth on hosts to increase, decrease, or remain constant; more work is needed to ascertain how density dependence operates in populations of $B$. dendrobatidis.

\section{Cold-induced zoospore release}

Seasonal variation and environmental conditions such as low temperatures can sometimes trigger disease emergence (Dobson and Carper 1992, Sternberg 1994, Bouma and Dye 1997, Epstein et al. 1998, Harvell et al. 1999, 2002, Daszak et al. 2000, Altizer et al. 2006). For example, winter saprolegniosis in channel catfish was caused by low temperatures favoring pathogen growth and concurrent immunosuppression in catfish (Bly et al. 1993). Climatic conditions are of particular interest given the history of amphibian population declines in areas protected from direct human disturbance (Weygoldt 1989, Pounds and Crump 1994, Pounds et al. 1997, 1999), including tropical high-elevation sites where climate change may have the greatest ecological impact (Schneider 1993, Diaz and Graham 1996, Beniston et al. 1997, Diaz and Bradley 1997, Thomas et al. 2004). Our 
data suggests that a cold shock could trigger disease emergence by temporarily increasing the population growth rate of $B$. dendrobatidis and increasing infectivity. Large numbers of infectious zoospores were released when temperatures dropped. After growing to maturesized thalli at $26.5^{\circ} \mathrm{C}$, zoospores may have been quickly produced and released within a few days of the onset of cold conditions (Fig. 2C). This experiment indicates that the course of development and maturation is not set at the time of zoospore encystment, but changes with temperature. Cold shocks may also affect host behavior and immune function.

\section{Host behavior in the cold}

Although the amphibian chytrid is well adapted to a range of temperatures between $8^{\circ}$ and $25^{\circ} \mathrm{C}$, host factors such as behavior and immune function may contribute to the development of fatal chytridiomycosis and disease-associated population declines at low temperatures. Batrachochytrium dendrobatidis has a direct life cycle and does not require an intermediate host (Longcore et al. 1999). An infected amphibian may shelter many generations of the pathogen, and pathogen spread over the host is perhaps facilitated in moist microhabitats and by low temperatures in which zoospores survive longer. Temperature strongly affects the activity patterns and microhabitat choices of ectotherms (Hutchison and Dupre 1992). The thermal environment of host amphibians affects the outcome of $B$. dendrobatidis infection (Woodhams et al. 2003, Berger et al. 2004). If high temperatures are available for basking, some amphibians may be able to inhibit fungal infections (Woodhams et al. 2003). Some behaviors of amphibians under cold conditions may increase their susceptibility to infection by $B$. dendrobatidis. At temperatures below $16^{\circ} \mathrm{C}$, the tropical frogs Litoria nannotis, L. rheocola, and Nyctimystes dayi in Queensland, Australia, often shelter in streams or streamside refuges (Hodgkison and Hero 2002, Retallick 2002). In Central America, association with aquatic habitat was a primary factor correlated with amphibian population declines (Lips et al. 2003) and may be linked to the emergence of chytridiomycosis (Lips et al. 2006). Many temperate amphibians and larvae overwinter in aquatic habitats, particularly at high elevations with short seasons for larval development (Pinder et al. 1992). Low temperatures concurrently affect host and pathogen, in this case, perhaps, to the advantage of $B$. dendrobatidis.

\section{Host immune suppression in the cold}

Research on ectotherms has shown that low temperatures can inhibit immune function (Bennett and Neville 1975, Cooper et al. 1992, Bly et al. 1993, Le Morvan et al. 1998, Carey et al. 1999, Jackson and Tinsley 2002). For some amphibians, short-term cold exposure as well as seasonal variability in temperature suppresses immune function. Maniero and Carey (1997) found that several immune defenses, including complement activity and lymphocyte proliferation, were suppressed in northern leopard frogs, Rana pipiens, by low temperatures. In African clawed frogs, Xenopus laevis, cold conditions increased the establishment of infection with the helminth parasite Protopolystoma xenopodis (Jackson and Tinsley 2002). Red-spotted newts, Notophothalmus viridescens, decreased leukocyte production and lysozyme activity in the cold (Raffel et al. 2006). Wood frogs, Rana sylvatica, stopped synthesis of antimicrobial peptides at low temperatures (Matutte et al. 2000). Our data suggest that immune defenses that target the infective zoospore stage may be critical at low temperatures.

Innate epithelial defenses such as regulation of skin sloughing and mucosal barriers including antimicrobial peptides and commensal microbiota may influence the parameters modeled here, particularly zoospore survival and encystment rates. These defenses may inhibit $B$. dendrobatidis infections in some species (Davidson et al. 2003, Rollins-Smith and Conlon 2005, Harris et al. 2006, Woodhams et al. 2006, 2007) and are likely to be affected by temperature. For example, the microbiota of four-toed salamanders, Hemidactylium scutatum, include bacteria that inhibit the growth of oophagus fungus and B. dendrobatidis (Harris et al. 2006). However, microbiota may vary with environmental conditions, as shown in the large intestine of hibernating and nonhibernating Rana pipiens (Carr et al. 1976, Gossling et al. 1982, Banas et al. 1988). The effectiveness of these innate skin defenses also varies with species.

Several host factors may influence disease emergence, including suppression of host defenses and changes in the occurrence of risky host behavior. The biogeographical patterns of disease emergence may not be simply defined by characteristics of the pathogen. Although the amphibian chytrid is well adapted to a range of temperatures up to $25^{\circ} \mathrm{C}$, host factors contribute to the diseaseassociated population declines at low temperatures.

\section{ACKNOWLEDGMents}

We thank R. Speare, L. Reinert, and the J. Chen laboratory for their helpful assistance. This research was supported by subcontracts to L. Rollins-Smith and R. A. Alford from NSF Integrated Research Challenges in Environmental Biology grants IBN-9977063 and DEB-0213851 (J. Collins, P.I.) and NSF grants IBN-0131184 and IOB-0520847 to L. A. RollinsSmith. D. C. Woodhams was supported by a Doctoral Research Scholarship, Supplementary Internal Research Account Scholarship, and International Post-Graduate Research Scholarship from James Cook University, and the Immunobiology of Blood and Vascular Systems Training Program (NIH 5 T32 HL069765-02; J. Hawiger, P.I.). C. J. Briggs was supported by NIH/NSF Ecology of Infectious Disease Program grant, R01 ES12067, from NIEHS.

\section{Literature Cited}

Altizer, S., A. Dobson, P. Hosseini, P. Hudson, M. Pascual, and P. Rohani. 2006. Seasonality and the dynamics of infectious disease. Ecology Letters 9:467-484.

Angilletta, M. J., Jr., and A. E. Dunham. 2003. The temperature-size rule in ectotherms: simple evolutionary 
explanations may not be general. American Naturalist 162: $332-342$.

Annis, S. L., F. P. Dastoor, H. Ziel, P. Daszak, and J. E. Longcore. 2004. A DNA-based assay identifies Batrachochytrium dendrobatidis in amphibians. Journal of Wildlife Diseases 40:420-428.

Banas, J. A., W. J. Loesche, and G. W. Nace. 1988. Classification and distribution of large intestinal bacteria in nonhibernating and hibernating leopard frogs (Rana pipiens). Applied and Environmental Microbiology 54:2305-2310.

Beniston, M., H. F. Diaz, and R. S. Bradley. 1997. Climatic change at high elevation sites: an overview. Climatic Change 36:233-251.

Bennett, M. F., and C. G. Neville. 1975. Effects of cold shock on the distribution of leucocytes in goldfish, Carassius auratus. Journal of Comparative Physiology 98:213-216.

Berger, L. 2001. Diseases in Australian frogs. Dissertation. School of Public Health and Tropical Medicine, James Cook University, Townsville, Australia.

Berger, L., A. D. Hyatt, R. Speare, and J. E. Longcore. 2005. Life cycle stages of the amphibian chytrid Batrachochytrium dendrobatidis. Diseases of Aquatic Organisms 68:51-63.

Berger, L., et al. 1998. Chytridioycosis causes amphibian mortality associated with population declines in the rain forests of Australia and Central America. Proceedings of the National Academy of Sciences (USA) 95:9031-9036.

Berger, L., et al. 2004. Effect of season and temperature on mortality in amphibians due to chytridiomycosis. Australian Veterinary Journal 82:434-439.

Berger, L., R. Speare, and A. Kent. 1999. Diagnosis of chytridiomycosis in amphibians by histologic examination. Zoo's Print Journal 15:184-190.

Blaustein, A. R., J. M. Romansic, E. A. Scheessele, B. A. Han, A. P. Pessier, and J. E. Longcore. 2005. Interspecific variation in susceptibility of frog tadpoles to the pathogenic fungus Batrachochytrium dendrobatidis. Conservation Biology 19:1460-1468.

Bly, J. E., L. A. Lawson, A. J. Szalai, and L. W. Clem. 1993. Environmental factors affecting outbreaks of winter saprolegniosis in channel catfish, Ictalurus punctatus (Rafinesque). Journal of Fish Diseases 16:541-549.

Bosch, J., and I. Martinez-Solano. 2006. Chytrid fungus infection related to unusual mortalities of Salamandra salamandra and Bufo bufo in the Penalara Natural Park, Spain. Oryx 40:84-89.

Bouma, M. J., and C. Dye. 1997. Cycles of malaria associated with El Nino in Venezuela. Journal of the American Medical Association 278:1772-1774.

Bradley, G. A., P. C. Rosen, M. J. Sredl, T. R. Jones, and J. E. Longcore. 2002. Chytridiomycosis in native Arizona frogs. Journal of Wildlife Diseases 38:206-212.

Carey, C., J. E. Bruzgul, L. J. Livo, M. L. Walling, K. A. Kuehl, B. F. Dixon, A. P. Pessier, R. A. Alford, and K. B. Rogers. 2006. Experimental exposures of boreal toads (Bufo boreas) to a pathogenic chytrid fungus (Batrachochytrium dendrobatidis). EcoHealth 3:5-21.

Carey, C., N. Cohen, and L. Rollins-Smith. 1999. Amphibian declines: an immunological perspective. Developmental and Comparative Immunology 23:459-472.

Carr, A. H., R. L. Amborski, D. D. Culley, Jr., and G. F. Ambrorski. 1976. Aerobic bacteria in the intestinal tracts of bullfrogs (Rana catesbeiana) maintained at low temperatures. Herpetologica 32:239-244.

Cooper, E. L., R. K. Wright, A. E. Klempau, and C. T. Smith. 1992. Hibernation alters the frog's immune system. Cryobiology 29:616-631.

Daszak, P., L. Berger, A. A. Cunningham, A. D. Hyatt, D. E. Green, and R. Speare. 1999. Emerging infectious diseases and amphibian population declines. Emerging Infectious Diseases 5:1-23.
Daszak, P., A. A. Cunningham, and A. D. Hyatt. 2000. Emerging infectious diseases of wildlife - threats to biodiversity and human health. Science 287:443-449.

Daszak, P., A. A. Cunningham, and A. D. Hyatt. 2003. Infectious disease and amphibian population declines. Journal of Diversity and Distributions 9:141-150.

Davidson, E. W., M. Parris, J. P. Collins, J. E. Longcore, A. P. Pessier, and J. Brunner. 2003. Pathogenicity and transmission of chytridiomycosis in tiger salamanders (Ambystoma tigrinum). Copeia 3:601-607.

Diaz, H. F., and R. S. Bradley. 1997. Temperature variations during the last century at high elevation sites. Climatic Change 36:253-279.

Diaz, H. F., and N. E. Graham. 1996. Recent changes in tropical freezing heights and the role of sea surface temperature. Nature 383:152-155.

Di Rosa, I., F. Simoncelli, A. Fagotti, and R. Pascolini. 2007. Ecology: The proximate cause of frog declines? Nature 447: E4-5.

Dobson, A., and R. Carper. 1992. Global warming and potential changes in host-parasite and disease-vector relationships. Pages 201-217 in R. L. Peters and T. E. Lovejoy, editors. Global warming and biological diversity. Yale University Press, New Haven, Connecticut, USA.

Drew, A., A. J. Allen, and L. J. Allen. 2006. Analysis of climatic and geographic factors affecting the presence of chytridiomycosis in Australia. Diseases of Aquatic Organisms 68:245250.

Epstein, P. R., H. F. Diaz, S. Elias, G. Grabherr, N. E. Graham, W. J. M. Martens, E. Mosley-Thompson, and J. Susskind. 1998. Biological and physical signs of climate change: focus on mosquito-borne diseases. Bulletin of the American Meteorological Society 79:409-416.

Gossling, J., W. J. Loesche, and G. W. Nace. 1982. Large intestine bacterial flora of nonhibernating and hibernating leopard frogs (Rana pipiens). Applied and Environmental Microbiology 44:59-66.

Gurney, W. S. C., S. Tobia, G. Watt, and H. Dobby. 1998. SOLVER. Revision 5.06. A program template for initial value problems expressible as sets of coupled ordinary or delay differential equations. 〈http://www.stams.strath.ac.uk/ ecodyn/solvman.html $\rangle$

Harris, R. N., T. Y. James, A. Lauer, M. A. Simon, and A. Patel. 2006. Amphibian pathogen Batrachochytrium dendrobatidis is inhibited by the cutaneous bacteria of amphibian species. EcoHealth 3:53-56.

Harvell, C. D., C. E. Mitchell, J. R. Ward, S. Altizer, A. P. Dobson, R. S. Ostfeld, and M. D. Samuel. 2002. Climate warming and disease risks for terrestrial and marine biota. Science 296:2158-2162.

Harvell, C. D., et al. 1999. Emerging marine diseases - climate links and anthropogenic factors. Science 285:1505-1510.

Hodgkison, S., and J.-M. Hero. 2002. Seasonal behaviour of Litoria nannotis, Litoria rheocola and Nyctimystes dayi in Tully Gorge, North Queensland, Australia. Pages 29-39 in A. Nattrass, editor. Frogs in the community: Proceedings of the Brisbane symposium 13-14 February 1999. Queensland Frog Society, Brisbane, Queensland, Australia.

Howe, R. W. 1967. Temperature effects on embryonic development in insects. Annual Review of Entomology 12: $15-42$.

Hutchison, V. H., and R. K. Dupre. 1992. Thermoregulation. Pages 206-249 in M. E. Feder and W. W. Burggren, editors. Environmental physiology of the amphibians. University of Chicago Press, Chicago, Illinois, USA.

Hyatt, A. D., et al. 2007. Diagnostic assays and sampling protocols for the detection of Batrachochytrium dendrobatidis. Diseases of Aquatic Organisms 73:175-192.

Jackson, J., and R. Tinsley. 2002. Effects of environmental temperature on the susceptibility of Xenopus laevis and $X$. 
wittei (Anura) to Protopolystoma xenopodis (Monogenea). Parasitology Research 88:632-638.

Kavanagh, K., and R. A. Alford. 2003. Sensory and skeletal development and growth in relation to the duration of embryonic and larval stages in damselfishes (Pomacentridae). Biological Journal of the Linnaean Society 80:187-206.

Le Morvan, C., D. Troutuad, and P. Deschaux. 1998. Differential effects of temperature on specific and nonspecific immune defences in fish. Journal of Experimental Biology 201:165-168.

Lips, K. R., F. Brem, R. Brenes, J. D. Reeve, R. A. Alford, J. Voyles, C. Carey, L. Livo, A. P. Pessier, and J. P. Collins. 2006. Emerging infectious disease and the loss of biodiversity in a Neotropical amphibian community. PNAS 103:31653170 .

Lips, K. R., J. D. Reeve, and L. R. Witters. 2003. Ecological traits predicting amphibian population declines in Central America. Conservation Biology 17:1078-1088.

Llodra, E. R. 2002. Fecundity and life-history strategies in marine invertebrates. Advances in Marine Biology 43:87170.

Longcore, J. E., A. P. Pessier, and D. K. Nichols. 1999. Batrachochytrium dendrobatidis gen. et sp. nov., a chytrid pathogenic to amphibians. Mycologia 91:219-227.

Maniero, G. D., and C. Carey. 1997. Changes in selected aspects of immune function in the leopard frog, Rana pipiens, associated with exposure to cold. Journal of Comparative Physiology B 167:256-263.

Matutte, B., K. B. Storey, F. C. Knoop, and J. M. Conlon. 2000. Induction of synthesis of an antimicrobial peptide in the skin of the freeze-tolerant frog, Rana sylvatica, in response to environmental stimuli. FEBS Letters 483:135138.

Morgan, J. A., V. T. Vredenburg, L. J. Rachowicz, R. A. Knapp, M. J. Stice, T. Tunstall, R. E. Bingham, J. M. Parker, J. E. Longcore, C. Moritz, C. J. Briggs, and J. W. Taylor. 2007. Population genetics of the frog-killing fungus Batrachochytrium dendrobatidis. Proceedings of the National Academy of Sciences (USA) 104:13845-13850.

Pinder, A. W., K. B. Storey, and G. R. Ultsch. 1992. Estivation and hibernation. Pages 250-276 in M. E. Feder and W. W. Burggren, editors. Environmental physiology of the amphibians. University of Chicago Press, Chicago, Illinois, USA.

Piotrowski, J. S., S. L. Annis, and J. E. Longcore. 2004. Physiology of Batrachochytrium dendrobatidis, a chytrid pathogen of amphibians. Mycologia 96:9-15.

Pounds, J. A., and M. L. Crump. 1994. Amphibian declines and climate disturbance: the case of the golden toad and the harlequin frog. Conservation Biology 8:72-85.

Pounds, J. A., M. P. L. Fogden, and J. H. Campbell. 1999. Biological response to climate change on a tropical mountain. Nature 398:611-615.

Pounds, J. A., M. P. L. Fogden, J. M. Savage, and G. C. Gorman. 1997. Tests of null models for amphibian declines on a tropical mountain. Conservation Biology 11:1307-1322.

Pounds, J. A., et al. 2006. Widespread amphibian extinctions from epidemic disease driven by global warming. Nature 439: 161-167.

Rachowicz, L. J., R. A. Knapp, J. A. T. Morgan, M. J. Stice, V. T. Vredenburg, J. M. Parker, and C. J. Briggs. 2006. Emerging infectious disease as a proximate cause of amphibian mass mortality. Ecology 87:1671-1683.

Raffel, T. R., J. R. Rohr, J. M. Kiesecker, and P. J. Hudson. 2006. Negative effects of changing temperature on amphibian immunity under field conditions. Functional Ecology 20:819828.
R Development Core Team. 2007. R: a language and environment for statistical computing. R Foundation for Statistical Computing, Vienna, Austria.

Retallick, R. 2002. Using experimental translocations to learn about declines in Queensland's frog populations. Final Report April 2002. Queensland Parks and Wildlife Service, Atherton, Queensland, Australia.

Retallick, R. W., H. McCallum, and R. Speare. 2004. Endemic infection of the amphibian chytrid fungus in a frog community post-decline. PLoS Biology 2:e351.

Rollins-Smith, L. A., and M. Conlon. 2005. Antimicrobial peptide defenses against chytridiomycosis, an emerging infectious disease of amphibian populations. Developmental and Comparative Immunology 29:589-598.

Ron, S. R. 2005. Predicting the distribution of the amphibian pathogen Batrachochytrium dendrobatidis in the new world. Biotropica 37:209-221.

Savage, V. M., J. F. Gillooly, J. H. Brown, G. B. West, and E. L. Charnov. 2004. Effects of body size and temperature on population growth. American Naturalist 163:429-441.

Schneider, S. H. 1993. Scenarios of global warming. Pages 9-23 in P. M. Kareiva, J. G. Kingsolver, and R. B. Huey, editors. Biotic interactions and global change. Sinauer, Sunderland, Massachusetts, USA.

Sisodia, S., and B. N. Singh. 2002. Effect of temperature on longevity and productivity in Drosophila ananassae: evidence for adaptive plasticity and tradeoff between longevity and productivity. Genetica 114:95-102.

Smith-Gill, S. J., and K. A. Berven. 1979. Predicting amphibian metamorphosis. American Naturalist 113:563-585.

Spencer, K. A., and D. M. Bryant. 2002. State-dependent behaviour in breeding barn swallows (Hirundo rustica): consequences for reproductive effort. Proceedings of the Royal Society B 269:403-410.

Sternberg, S. 1994. The emerging fungal threat. Science 266: $1632-1634$.

Stuart, S. N., J. S. Chanson, N. A. Cox, B. E. Young, A. S. L. Rodrigues, D. L. Fischman, and R. W. Waller. 2004. Status and trends of amphibian declines and extinctions worldwide. Science 306:1783-1786.

Thomas, C. D., et al. 2004. Extinction risk from climate change. Nature 427:145-148.

Werner, E. E. 1986. Amphibian metamorphosis: growth rate, predation risk, and the optimal size at transformation. American Naturalist 128:319-341.

Weygoldt, P. 1989. Changes in the composition of mountain stream frog communities in the Atlantic mountains of Brazil: Frogs as indicators of environmental deteriorations? Studies on Neotropical Fauna and Environment 243:249-255.

Wilbur, H. M., and J. P. Collins. 1973. Ecological aspects of amphibian metamorphosis. Science 182:1305-1314.

Woodhams, D. C., and R. A. Alford. 2005. Ecology of chytridiomycosis in rainforest stream frog assemblages of tropical Queensland. Conservation Biology 19:1449-1459.

Woodhams, D. C., R. A. Alford, and G. Marantelli. 2003. Emerging disease of amphibians cured by elevated body temperature. Diseases of Aquatic Organisms 55:65-67.

Woodhams, D. C., K. Ardipradja, R. A. Alford, G. Marantelli, L. K. Reinert, and L. A. Rollins-Smith. 2007. Resistance to chytridiomycosis varies among amphibian species and is correlated with skin peptide defenses. Animal Conservation 10:409-417.

Woodhams, D. C., J. P. Ramsey, and L. A. Rollins-Smith. 2006. Effects of cold temperature on antimicrobial peptide synthesis and release in northern leopard frogs, Rana pipiens. Integrative and Comparative Biology 45:1099. 